\title{
Effects of Kikuyu grass (Pennisetum clandestinum) age and different forage: concentrate ratios on methanogenesis
}

\section{Efecto de la edad del pasto kikuyo (Pennisetum clandestinum) y la relación forraje: concentrado sobre la metanogénesis}

\author{
John Ramírez, ${ }^{1}$ M.Sc, Sandra Posada O, ${ }^{1 *}$ Ph.D, Ricardo Noguera, ${ }^{1}$ Ph.D.
}

${ }^{1}$ Universidad de Antioquia, Facultad de Ciencias Agrarias, Grupo de Investigación en Ciencias AgrariasGRICA, AA 1226, Medellín, Colombia. *Correspondencia: slposada@gmail.com

Received: September 2014; Accepted: February 2015.

\begin{abstract}
Objective. To evaluate the effect of Kikuyu grass (Pennisetum clandestinum) harvested at two different ages and three forage: concentrate supplement ratios $(\mathrm{F} / \mathrm{C})$ on methane $\left(\mathrm{CH}_{4}\right)$ production, dry matter digestibility (DMD), and fermentation profile using the in vitro gas production technique. Materials and methods. six treatments, resulting from the combination of pasture age (30 or 60 days) and F/C $(100 / 0,75 / 25$, or $50 / 50)$ were evaluated using a $2 \times 3$ factorial design. The response variables were measured 6,12, 24 and 48 hours after incubation. A repeated-measure over time design was used to analyze the data, and differences between means were determined with the LSMEANS procedure of SAS. Results. the youngest grass (30 days) was more digestible, produced less $\mathrm{CH}_{4}$ per gram of digestible dry matter $\left({ }_{d} \mathrm{DM}\right)$ and more total volatile fatty acids (VFA) compared to the oldest grass (60 days; $p<0.05$ ). Reductions of the $\mathrm{F} / \mathrm{C}$ ratio increased $\mathrm{DMD}$ and $\mathrm{CH}_{4}$ production per gram of ${ }_{\mathrm{d}} \mathrm{DM}$ $(p<0.05)$ but had no significant effect on VFA concentration $(p>0.05)$. Conclusions. under in vitro conditions and $\mathrm{pH}$ close to neutrality, the older grass reduces DMD and increases $\mathrm{CH}_{4}$ production per gram of ${ }_{d} \mathrm{DM}$, while a $\mathrm{F} / \mathrm{C}$ reduction increases $\mathrm{DMD}$ and $\mathrm{CH}_{4}$ production per gram of ${ }_{\mathrm{d}} \mathrm{DM}$, which differs with reports conducted in vivo.
\end{abstract}

Key words: Carbohydrates, in vitro digestibility, grass maturity, methane production (Sources: $C A B$, USDA).

\section{RESUMEN}

Objetivo. Evaluar el efecto de la edad del pasto kikuyo (Pennisetum clandestinum) y de la relación forraje/suplemento ( $\mathrm{F} / \mathrm{S})$ sobre la producción de metano $\left(\mathrm{CH}_{4}\right)$, la digestibilidad de la materia seca (DMS) y el perfil de fermentación mediante la técnica in vitro de producción de gas. Materiales y métodos. Seis tratamientos, resultantes de la combinación de los factores edad del pasto (30 y 60 días) y relación $\mathrm{F} / \mathrm{S}(100 / 0,75 / 25$ y 50/50), fueron evaluados bajo un diseño factorial $2 \times 3$. Las variables respuesta se midieron a las $6,12,24$ y 48 horas de incubación. Para el análisis de los datos se empleó un diseño de medidas repetidas en el tiempo y las diferencias entre medias se determinaron con el procedimiento LSMEANS de SAS. Resultados. El pasto de menor edad (30 días) fue más digestible, produjo menos $\mathrm{CH}_{4}$ por gramo de materia seca digestible $\left(\mathrm{MS}_{\mathrm{d}}\right)$ y más ácidos grasos volátiles totales $(\mathrm{AGV})$ que el pasto de mayor edad (60 días, $\mathrm{p}<0.05)$. La reducción en la relación $\mathrm{F} / \mathrm{S}$ aumentó la DMS y la producción de $\mathrm{CH}_{4}$ por gramo de $\mathrm{MS}_{\mathrm{d}}(\mathrm{p}<0.05)$, pero no tuvo efecto estadístico 
sobre la concentración de AGV ( $p>0.05)$. Conclusiones. Bajo condiciones in vitro, con pH próximo a la neutralidad, la mayor edad del pasto reduce la DMS y aumenta la producción de $\mathrm{CH}_{4}$ por gramo de $\mathrm{MS}_{\mathrm{d}}$, mientras que la reducción en la relación F/S aumenta la DMS y la producción de $\mathrm{CH}_{4}$ por gramo de $\mathrm{MS}_{\mathrm{d}}$, último hallazgo que contrasta con los reportes in vivo.

Palabras clave: Carbohidratos, digestibilidad in vitro, estado de madurez, producción de metano (Fuentes: $C A B, U S D A$ ).

\section{INTRODUCTION}

Methane $\left(\mathrm{CH}_{4}\right)$ is one of the main products of ruminal fermentation. It is considered a greenhouse gas (GHG) and represents between 2 and $15 \%$ of the energy consumed by ruminants (1). $\mathrm{CH}_{4}$ is produced in the rumen by a group of microorganisms of the Archaea domain, which use hydrogen $\left(\mathrm{H}_{2}\right)$ to reduce carbon dioxide $\left(\mathrm{CO}_{2}\right)$ to $\mathrm{CH}_{4}$, maintaining a low $\mathrm{H}_{2}$ pressure that favors fermentation processes (2).

Most dairy farms in Colombia are based on Kikuyu grass (Pennisetum clandestinum) as the main grazing grass for the animals. Average levels of neutral detergent fiber (NDF), nonstructural carbohydrates (NSC) and crude protein (CP) in Kikuyu are 58.1, 13.4, and $20.5 \%$, respectively (on a dry matter bases (DM)) and fluctuate depending on the agronomic management (3). Because of its composition, Kikuyu grass presents nutritional constraints affecting milk yield and quality. Thus, supplements are commonly offered to improve the availability of NSC and energy in the rumen.

Feeding concentrate supplements to grazing ruminants is associated with a reduction of $\mathrm{CH}_{4}$ emissions. A change in the relationship feed: concentrate (DM bases) from 47: 53 to 68: 32 increased $\mathrm{CH}_{4}$ emissions from 538 to $648 \mathrm{~g} / \mathrm{cow} /$ day (4). Different carbohydrates change the volatile fatty acids (VFA) profile and the production of $\mathrm{CH}_{4}$. Cellulose and starch degradation leads to glucose formation, which can be fermented in different pathways resulting in varying amounts of $\mathrm{H}_{2}$. The production of $\mathrm{CH}_{4}$ per unit of food digested depends on the amount of $\mathrm{H}_{2}$ formed, according to the stoichiometric ratio $4 \mathrm{H}_{2}+\mathrm{CO}_{2} \rightarrow \mathrm{CH}_{4}+2 \mathrm{H}_{2} \mathrm{O}$. The formation of acetate and butyrate results in 1 and 0.5 moles of $\mathrm{CH}_{4}$ per mole of fermented glucose, respectively. On the other hand, propionate formation requires a net input of reduced equivalents, decreasing $\mathrm{CH}_{4}$ production. Fiber fermentation results in the preferential production of acetate, while feeding NSC increases the proportion of propionate (2). The objective of this study was to determine the effect of Kikuyu grass (Pennisetum clandestinum) harvested at two different ages and three forage: concentrate

\section{INTRODUCCIÓN}

El metano $\left(\mathrm{CH}_{4}\right)$ es uno de los principales productos de la fermentación ruminal y además de contribuir a las emisiones de gases de efecto invernadero (GEI) representa entre 2 y $15 \%$ de la energía consumida por el rumiante (1). $\mathrm{El} \mathrm{CH}_{4}$ es producido en el rumen por un grupo particular de microorganismos pertenecientes al dominio Archaea, los cuales usan hidrógeno $\left(\mathrm{H}_{2}\right)$ para reducir el dióxido de carbono $\left(\mathrm{CO}_{2}\right)$ a $\mathrm{CH}_{4}$, manteniendo una presión baja de $\mathrm{H}_{2}$ que favorece la fermentación de los alimentos (2).

En la mayoría de los sistemas especializados de producción lechera en Colombia se utiliza el pasto kikuyo (Pennisetum clandestinum) como base forrajera para la alimentación de los animales. Correa et al (3), reportaron que el pasto kikuyo posee contenidos medios de fibra detergente neutra (FDN), carbohidratos no estructurales (CNE) y proteína bruta (PB) de $58.1,13.4$ y $20.5 \%$ de la materia seca (MS), respectivamente, valores que fluctúan en función del manejo agronómico. Esta composición química hace que el pasto kikuyo presente limitaciones nutricionales que afectan la producción y calidad de la leche, siendo necesaria la utilización de suplementos que mejoren la disponibilidad de CNE y de energía en el rumen.

La utilización de suplementos concentrados en las dietas para rumiantes, las cuales están basadas en forrajes, está asociada con reducción en la emisión de $\mathrm{CH}_{4}$, lo cual fue evidenciado en el trabajo de Aguerre et al (4), donde el cambio en la relación forraje:concentrado (con base en la materia seca) de 47:53 a 68:32 incrementó la emisión de $\mathrm{CH}_{4}$ de 538 a $648 \mathrm{~g} / \mathrm{vaca} /$ día. Diferentes tipos de carbohidratos modifican el perfil de ácidos grasos volátiles (AGV) y, por tanto, la producción de $\mathrm{CH}_{4}$. La degradación de la celulosa y el almidón conduce a la formación de glucosa, la cual se fermenta por diferentes vías, resultando en variable cantidad de $\mathrm{H}_{2}$. La producción de $\mathrm{CH}_{4}$ por unidad de alimento digerido depende de la cantidad de $\mathrm{H}_{2}$ formado, con base en la relación estequiométrica $4 \mathrm{H}_{2}+\mathrm{CO}_{2} \rightarrow \mathrm{CH}_{4}+2 \mathrm{H}_{2} \mathrm{O}$. La formación de acetato y butirato resulta en la producción de 1 y 0.5 moles de $\mathrm{CH}_{4}$ por mol de glucosa fermentada, respectivamente; mientras que la formación de propionato requiere un ingreso neto de equivalentes reducidos, disminuyendo la producción de $\mathrm{CH}_{4}$. La fermentación de la fibra resulta en la producción preferente de acetato, 
supplement ratios $(\mathrm{F} / \mathrm{C})$ on methane $\left(\mathrm{CH}_{4}\right)$ production, dry matter digestibility (DMD), and fermentation profile using the in vitro gas production technique.

\section{MATERIALS AND METHODS}

Location. The study was conducted at the Nutrition and Animal Feeding Laboratory facilities of Universidad de Antioquia, Medellin, Colombia.

Substrates and chemical analysis. The substrates tested were Kikuyu grass (Pennisetum clandestinum) and a commercial concentrate supplement formulated for dairy cows. The grass was harvested at Betania farm, owned by Solla SA Company, during vegetative stage by cutting it $10 \mathrm{~cm}$ above the ground at 30 and 60 days of age. This farm is located in Santa Rosa de Osos municipality (Ant., Colombia) at 2460 m.a.s.l., with $18^{\circ} \mathrm{C}$ average temperature (range: 4 to $27^{\circ} \mathrm{C}$ ), $70 \%$ relative humidity and $2400 \mathrm{~mm}$ average annual precipitation, corresponding to a lower montane wet forest (LMWF). The pasture was managed under a rotational grazing system with chemical fertilization (190,54, 16, and 9 $\mathrm{kg} \mathrm{N}, \mathrm{P}, \mathrm{K}$, and $\mathrm{S} / \mathrm{ha}$ /year).

Grass samples were dried in forced air oven at $65^{\circ} \mathrm{C}$ for 48 hours. Grass and supplement samples were ground to $1 \mathrm{~mm}$ for chemical analysis including DM, CP, ether extract (EE), ash (5), NDF (6), acid detergent fiber (ADF), acid detergent lignin (ADL) (7) and gross energy (GE). The GE was assessed in an adiabatic bomb calorimeter (IKA C5000, Rhys International Ltd., United Kingdom). NSC values were obtained by the equation, $N S C=100-(\% C P+\% E E+\% A s h \% N D F)(8)$. The chemical description of substrates is presented in table 1.

Table 1. Chemical composition of Kikuyo grass (Pennisetum clandestinum) concentrate supplement used in the study.

\begin{tabular}{lccc} 
Fraction (\% DM) & Kikuyo (30 d) & Kikuyo (60 d) & Supplement \\
\hline CP & 25.4 & 17.0 & 16.1 \\
EE & 4.1 & 3.2 & 3.0 \\
Ash & 9.0 & 12.0 & 5.1 \\
NDF & 53.8 & 61.6 & 11.1 \\
ADF & 29.7 & 34.0 & 6.9 \\
ADL & 5.4 & 6.5 & 1.3 \\
NSC & 7.7 & 6.2 & 64.7 \\
NSC/NDF & 0.14 & 0.10 & 5.83 \\
GE Mcal/kg DM & 4.4 & 4.1 & 4.3 \\
\hline
\end{tabular}

en tanto la alimentación con CNE aumenta la proporción de propionato (2). El objetivo del presente trabajo fue determinar como la producción de $\mathrm{CH}_{4}$, la digestibilidad de la MS (DMS) y el perfil de fermentación son afectados por la edad del pasto kikuyo (Pennisetum clandestinum) y la relación forraje:suplemento $(\mathrm{F} / \mathrm{S})$.

\section{MATERIALES Y MÉTODOS}

Localización. Las pruebas se realizaron en el Laboratorio de Investigación en Nutrición y Alimentación Animal de la Universidad de Antioquia, Medellín-Colombia.

Sustratos incubados y análisis químico. Los sustratos fueron pasto kikuyo (Pennisetum clandestinum), y un suplemento comercial para vacas en producción. El pasto fue cosechado en estadio vegetativo, a $10 \mathrm{~cm}$ sobre el nivel del suelo, a los 30 y 60 días de edad en la hacienda Betania, propiedad de la empresa SOLLA, S.A. Esta hacienda se encuentra ubicada en el municipio de Santa Rosa de Osos (Ant., Colombia), a 2460 msnm, presenta temperatura promedio de $18^{\circ} \mathrm{C}$, variando entre $4^{\circ} \mathrm{C}$ y $27^{\circ} \mathrm{C}$, humedad relativa correspondiente al $70 \%$ y precipitación media anual de $2400 \mathrm{~mm}$, características correspondientes a un bosque muy húmedo montano bajo (bmh-MB). El pasto fue manejado bajo un sistema de pastoreo rotacional con fertilización química (190, 54,16 y 9 kg de N, P, K y S/Ha/año).

Las muestras de pasto fueron secadas en estufa de ventilación forzada a $65^{\circ} \mathrm{C}$ por 48 horas. Estas muestras y las de suplemento fueron molidas a 1 $\mathrm{mm}$ para su análisis químico, que incluyó $\mathrm{MS}, \mathrm{PB}$, extracto etéreo (EE), cenizas (Ce) (5), FDN (6), fibra detergente ácida (FDA), lignina detergente ácida (LDA) (7) y energía bruta (EB), última determinación realizada en bomba calorimétrica adiabática (IKA C5000, Rhys International, Ltd., United Kingdom). Los valores de CNE fueron obtenidos por la ecuación, $\mathrm{CNE}=100-(\% \mathrm{~PB}+\% \mathrm{EE}+\% \mathrm{Ce}+\% \mathrm{FDN})(8) . \mathrm{La}$ descripción química de los sustratos se presenta en la tabla 1.

Tratamientos experimentales. Se evaluaron seis tratamientos, resultantes de la combinación de los factores edad del pasto (30 y 60 días) y nivel de inclusión de suplemento concentrado $(0,25$ y $50 \%)$, en un diseño factorial $2 \times 3$. Los tratamientos fueron: K30-100/0, K30-75/25, K30-50/50, K60-100/0, K60$75 / 25$ y K60-50/50. K30 y K60 corresponden a la edad del pasto kikuyo y $100 / 0,75 / 25$ y $50 / 50$ a la relación F/S (con base en la materia seca). Cada tratamiento contó con tres repeticiones, correspondientes a tres fuentes de inóculo ruminal, cada uno obtenido de un animal diferente. 
Experimental treatments. Six treatments, resulting from the combination of pasture age (30 to 60 days) and inclusion level of concentrate supplement $(0,25$ and $50 \%)$ were evaluated in a $2 \times 3$ factorial design. The treatments were: $\mathrm{K} 30-100 / 0, \mathrm{~K} 30-75 / 25, \mathrm{~K} 30-$ $50 / 50$, K60-100/0, K60-75/25, and K60-50/50. Descriptors $\mathrm{K} 30$ and K60 correspond to Kikuyu age, while $100 / 0,75 / 25$ and $50 / 50$ to the $F / C$ ratio (DM basis). Treatments were replicated three times, corresponding to three sources of ruminal inoculum, each obtained from a different animal.

Gas production technique. This technique was conducted following protocols by Posada et al (9). Grass and concentrate supplement were ground to $1 \mathrm{~mm}$ and added $(0.5 \mathrm{~g})$ to each flask $(100 \mathrm{ml})$ according to the percentages set for each treatment.

The inocula were obtained from three Holstein Friesian adult cows from La Montaña farm, owned by Universidad de Antioquia (San Pedro de los Milagros, Ant., Colombia). The cows were grazing on 42 days old Kikuyu and were provided mineralized salt and water ad libitum. The inocula were collected in the morning (6:00 AM) and transported in thermos preheated with $40^{\circ} \mathrm{C}$ water to the laboratory, where they were filtered through a cotton mesh, gassed with $\mathrm{CO}_{2}$ and kept in a warm water bath during inoculation.

Preparation of the buffer solution followed recommendations by McDougall (10), using a $9 / 1(45 / 5 \mathrm{ml} / \mathrm{ml})$ buffer/inoculum ratio and (1M) citric acid was added to the mixture to obtain pH 6.5 (11). The flasks were sealed with rubber stoppers and stored in a forced-air oven at $39^{\circ} \mathrm{C}$ throughout the fermentation process.

Total gas and $\mathbf{C H}_{4}$. Total gas and $\mathrm{CH}_{4}$ production was determined at 6, 12, 24 and 48 $h$ of incubation. Gas pressure generated in the incubation flasks was measured with a digital transducer (Ashcroft 2089QG - Precision Digital Test Gauges, Stratford, CT, USA) and the PSI readings were converted to volume $(\mathrm{ml})$ using the equation

$Y=-0.1833+0.0598 X^{2}(9)$.

After reading the pressure, the generated gas was removed from the flasks using a plastic syringe and then stored in plastic bags for later $\mathrm{CH}_{4}$ analysis. For this purpose, gas samples $(100 \mu \mathrm{l})$ were taken with a gas-tight syringe and manually injected into a gas chromatograph (Thermo TRACE GC UItra ${ }^{\mathrm{TM}}$, Thermo Scientific, USA) equipped with a flame
Técnica de producción de gases. La técnica de producción de gases fue realizada siguiendo los protocolos de Posada et al (9). En cada frasco (de 100 $\mathrm{ml}$ ) se adicionó $0.5 \mathrm{~g}$ de sustrato molido a $1 \mathrm{~mm}$ (pasto y/o suplemento), de acuerdo con la participación porcentual de cada alimento en los tratamientos experimentales.

Los inóculos fueron obtenidos de tres vacas Holstein Fresian adultas pertenecientes a la hacienda $\mathrm{La}$ Montaña, propiedad de la Universidad de Antioquia (San Pedro de los Milagros, Ant., Colombia). La dieta de los animales donadores consistió de pasto kikuyo de 42 días de edad, sal mineralizada y agua a voluntad. Los inóculos se colectaron en la mañana (6:00 am) y su transporte hasta el laboratorio se realizó en termos precalentados con agua a $40^{\circ} \mathrm{C}$. En el laboratorio, los inóculos fueron filtrados a través de una malla de algodón, gaseados con $\mathrm{CO}_{2}$ y conservados en baño maría durante el proceso de inoculación.

La solución tampón (buffer) se preparó de acuerdo con las recomendaciones de McDougall (10), se utilizó una relación buffer/inóculo de $9 / 1(45 / 5 \mathrm{ml} / \mathrm{ml})$ y la mezcla fue acidificada con ácido cítrico $(1 M)$ hasta obtener $\mathrm{pH}$ 6.5 (11). Los frascos fueron cerrados con tapones de caucho y almacenados en estufa de ventilación forzada a $39^{\circ} \mathrm{C}$ durante todo el proceso fermentativo.

Determinación de la producción de gas y de $\mathrm{CH}_{4}$. La producción total de gas y de $\mathrm{CH}_{4}$ fue determinada luego de $6,12,24$ y $48 \mathrm{~h}$ de incubación. La presión generada en los frascos de incubación se midió con un transductor digital (Ashcroft 2089QG - Precision Digital Test Gauges, USA) y el valor obtenido (psi) fue transformado a volumen $(\mathrm{ml})$ con la ecuación.

$Y=-0.1833+5.2098 X+0.0598 X^{2}(9)$.

Luego de la lectura de presión, el gas generado fue retirado de los frascos usando jeringa plástica y almacenado en bolsas plásticas para posterior análisis de $\mathrm{CH}_{4}$. Para tal efecto, muestras de $100 \mu \mathrm{l}$ de gas fueron tomadas con una jeringa hermética para gas e inyectadas manualmente en un cromatógrafo de gases (Thermo TRACE GC Ultra ${ }^{\mathrm{TM}}$, Thermo Scientific, USA) equipado con un detector de ionización de llama (FID). Las condiciones cromatográficas correspondieron a una columna apolar de $30 \mathrm{~m}, 0.32 \mathrm{~mm}$ y $0.25 \mu \mathrm{m}$, temperatura del puerto de inyección $200^{\circ} \mathrm{C}$, modo de inyección split (división) 50:1, temperatura del detector $250^{\circ} \mathrm{C}$, temperatura del horno $30^{\circ} \mathrm{C}(5 \mathrm{~min})$ hasta alcanzar $200^{\circ} \mathrm{C}\left(30^{\circ} \mathrm{C} / \mathrm{min}\right)$ y helio como gas de arrastre $(1.0 \mathrm{ml} / \mathrm{min})$. Los datos de concentración de metano fueron procesados de acuerdo con la descripción de López y Newbold (12). La producción de $\mathrm{CH}_{4}(\mathrm{ml})$ fue calculada a partir del volumen total de gas (ml) y la concentración de $\mathrm{CH}_{4}$. La producción de gas y de $\mathrm{CH}_{4}(\mathrm{ml})$ se expresó por gramo de materia seca incubada $\left(\mathrm{MS}_{\mathrm{i}}\right)$ y por gramo de materia seca 
ionization detector (FID). The chromatographic conditions corresponded to a $30 \mathrm{~m}$ nonpolar column, $0.32 \mathrm{~mm}$ and $0.25 \mu \mathrm{m}, 200^{\circ} \mathrm{C}$ injection port temperature, 50: 1 split injection mode, $250^{\circ} \mathrm{C}$ detector temperature, $30^{\circ} \mathrm{C}(5 \mathrm{~min})$ up to $200^{\circ} \mathrm{C}\left(30^{\circ} \mathrm{C} / \mathrm{min}\right)$ oven temperature, and helium as a carrier gas $(1.0 \mathrm{ml} / \mathrm{min})$. $\mathrm{CH}_{4}$ data were processed according to Lopez and Newbold (12). $\mathrm{CH}_{4}$ production ( $\mathrm{ml}$ ) was calculated from total gas volume $(\mathrm{ml})$ and $\mathrm{CH}_{4}$ concentration. Gas and $\mathrm{CH}_{4}$ production ( $\mathrm{ml}$ ) was expressed per gram of incubated dry matter ( $\mathrm{DM})$ and per gram of digestible dry matter $\left({ }_{d} D M\right) . C_{4}$ production was also expressed as a percentage of the incubated GE $(\mathrm{GE})$ and incubated digestible energy $(\mathrm{DE})$, giving $\mathrm{CH}_{4}$ a caloric value of $9.45 \mathrm{kcal} / \mathrm{L}$ (13).

Dry matter digestibility. DMD was determined gravimetrically at the times of gas pressure readings by filtering the incubation flasks contents using glass crucibles (porosity 1, 100$160 \mu \mathrm{m}$ ) and a vacuum pump. The residues were dried in the crucibles at $60^{\circ} \mathrm{C}$ for 48 hours in a forced-air oven and weighed.

Fermentation profile and $\mathbf{p H}$. The $\mathrm{pH}$ and concentration of acetic, propionic and butyric acids were determined in the liquid after filtration. This liquid was preserved by adding sulfuric acid ( $98 \% \mathrm{v} / \mathrm{v}$ ) until $\mathrm{pH} 2$ was reached. The $\mathrm{pH}$ was determined with digital $\mathrm{pH}$ meter (Handylab pH 1, Schott ${ }^{\circledR}$ Instruments, SI Analytics $\mathrm{GmbH}$, Germany) before acidification.

To determine VFA, liquid samples $(1 \mu \mathrm{l})$ were injected into a gas chromatograph (Thermo TRACE GC Ultra ${ }^{\mathrm{TM}}$, Thermo Scientific, USA) equipped with a $30 \mathrm{~m}, 0.32 \mathrm{~mm}$ and 0.25 microns column. Temperatures were $300^{\circ} \mathrm{C}$ (FID), $210^{\circ} \mathrm{C}$ (inlet), and $68^{\circ} \mathrm{C}(1 \mathrm{~min})$, ramp $10^{\circ} \mathrm{C} / \mathrm{min}$ until reaching $140^{\circ} \mathrm{C}$ (1 $\mathrm{min})$, ramp $40^{\circ} \mathrm{C} / \mathrm{min}$ until reaching $200^{\circ} \mathrm{C}(1$ min) (oven). The mode of injection was split and helium was used as a carrier gas $(2.5 \mathrm{ml} / \mathrm{min})$.

Statistical analysis. A repeated measures analysis was performed using PROC MIXED of SAS (14). The fixed effects of the model were grass, $F / C$, and incubation time; the random effect was the ruminal inoculum. Treatment means were compared using PROC LSMEANS of SAS (14).

\section{RESULTS}

Table 2 shows the chemical composition of the treatments. The 30 days-old grass had higher $C P$ and NSC content, but lower NDF, ADF and ADL compared to 60 days. The NSC/NDF ratio increased as concentrate increased in the mix. digestible $\left(\mathrm{MS}_{\mathrm{d}}\right)$. La producción de $\mathrm{CH}_{4}$ fue también expresada como porcentaje de la EB incubada (EB ${ }_{i}$ ) y energía digestible incubada $\left(E D_{i}\right)$, asignando al $\mathrm{CH}_{4}$ un valor calórico de $9.45 \mathrm{Kcal} / \mathrm{L}$ (13).

Determinación de la digestibilidad de la materia seca. En los horarios definidos para las lecturas de presión de gas, se determinó la DMS por gravimetría. Para esto, el contenido de los frascos de incubación se filtró utilizando crisoles de vidrio (porosidad 1, $100-160 \mu \mathrm{m}$ ) con ayuda de bomba de vacío. El conjunto crisol-residuo fue secado a $60^{\circ} \mathrm{C}$ durante 48 horas en estufa de ventilación forzada y posteriomente pesado.

\section{Determinación del perfil de fermentación y} pH. El valor de $\mathrm{pH}$ y la concentración de los ácidos acético, propiónico y butírico se determinaron en el líquido resultante de la filtración. Este líquido se preservó mediante la adición de ácido sulfúrico $(98 \% \mathrm{v} / \mathrm{v})$ hasta alcanzar un $\mathrm{pH} 2$. Antes de la acidificación, se determinó el pH con pH-metro digital (Handylab pH 1, Schott ${ }^{\circledR}$ Instruments, SI Analytics $\mathrm{GmbH}$, Germany).

Para la determinación de AGV, muestras de 1 $\mu l$ de líquido se inyectaron en un cromatógrafo de gases (Thermo TRACE GC UltraTM, Thermo Scientific, USA) equipado con una columna de 30 $\mathrm{m}, 0.32 \mathrm{~mm}$ y $0.25 \mu \mathrm{m}$. La temperaturas fueron $300^{\circ} \mathrm{C}$ (detector FID), $210^{\circ} \mathrm{C}$ (inyector) y $68^{\circ} \mathrm{C}$ (1 min), rampa de $10^{\circ} \mathrm{C} / \mathrm{min}$ hasta $140^{\circ} \mathrm{C}(1$ min), rampa de $40^{\circ} \mathrm{C} / \mathrm{min}$ hasta $200^{\circ} \mathrm{C}(1 \mathrm{~min})$ (horno). El modo de inyección fue split y como gas de arrastre se utilizó helio $(2.5 \mathrm{ml} / \mathrm{min})$.

Análisis estadístico. Se realizó un análisis de medidas repetidas en el tiempo a través de PROC MIXED de SAS (14). Los efectos fijos en el modelo correspondieron a la edad del pasto, la relación F/S y el tiempo de incubación; el efecto aleatorio estuvo representado por el inoculo ruminal. Las medias de tratamientos fueron comparadas con el procedimiento PROC LSMEANS de SAS (14).

\section{RESULTADOS}

En la tabla 2 se presenta la composición química de los diferentes tratamientos. Aquellos que incluyeron el pasto de 30 días de edad, respecto al de 60 días, presentaron mayor contenido de $\mathrm{PB}$ y CNE y menor porcentaje de FDN, FDA y LDA. A medida que se incrementó la participación de suplemento en la mezcla, aumentó la relación CNE/FDN.

En las tablas 3 y 4 se observa que la edad del pasto afectó significativamente $(p<0.05)$ la DMS, la producción acumulada de gas y de $\mathrm{CH}_{4}$ por gramo de $\mathrm{MS}_{\mathrm{d}} \mathrm{y}$ el porcentaje de ED 
Table 2. Chemical composition of kikuyo grass(Pennisetum clandestinum) aged 30 or 60 days and mixed with a concentrate supplement ${ }^{1}$.

\begin{tabular}{ccccccc}
\hline \multirow{2}{*}{ Fraction (\% DM) } & \multicolumn{3}{c}{ K30 } & \multicolumn{5}{c}{ K60 } \\
\cline { 2 - 7 } & $\mathbf{1 0 0 / 0}$ & $\mathbf{7 5 / 2 5}$ & $\mathbf{5 0 / 5 0}$ & $\mathbf{1 0 0 / 0}$ & $\mathbf{7 5 / 2 5}$ & $\mathbf{5 0 / 5 0}$ \\
\hline CP & 25.4 & 23.1 & 20.6 & 17.0 & 16.7 & 16.5 \\
EE & 4.1 & 3.8 & 3.6 & 3.2 & 3.2 & 3.1 \\
Ash & 9.0 & 8.0 & 7.1 & 12.0 & 10.3 & 8.6 \\
NDF & 53.8 & 43.1 & 32.5 & 61.6 & 49.0 & 36.4 \\
ADF & 29.7 & 24.0 & 18.3 & 34.0 & 27.2 & 20.5 \\
ADL & 5,4 & 4.4 & 3.4 & 6.5 & 5.2 & 3.9 \\
NSC & 7.7 & 22.0 & 36.2 & 6.2 & 20.8 & 35.4 \\
NSC/NDF & 0.14 & 0.51 & 1.11 & 0.10 & 0.42 & 0.97 \\
GE Mcal/kg DM & 4.4 & 4.4 & 4.4 & 4.1 & 4.2 & 4.2 \\
\hline
\end{tabular}

${ }^{1}$ Ingredients: Corn, malt germ, wheat bran, rice flour, sunflower meal, soybean meal, molasses, salt, premix, and calcium carbonate.

Tables 3 and 4 show that grass age significantly $(p<0.05)$ affected DMD, cumulative production of gas and $\mathrm{CH}_{4}$ per gram of ${ }_{\mathrm{d}} \mathrm{DM}$, and the percentage of $\mathrm{DE}$ transformed into $\mathrm{CH}_{4}$. Following 48 hours of incubation, the 30 days old grass showed greater DMD (68.97 vs. $65.30 \%)$, decreased production of gas (463.56 vs. $499.27 \mathrm{ml}$ ) and $\mathrm{CH}_{4}(101.37 \mathrm{ml}$ vs. 109.97) per gram of ${ }_{d} \mathrm{DM}$, and lower production of $\mathrm{CH}_{4}$ as a percentage of $\mathrm{DE}$ (22.83 vs. $24.70 \%$ ) compared with the 60 days grass.

The $\mathrm{F} / \mathrm{C}$ ratio significantly affected all variables $(p<0.05)$. The F/C presented a growing trend as grass was reduced and concentrate increased between 0 and 48 hours of incubation. The average incubada que se transformó en $\mathrm{CH}_{4}$. Al término de las 48 horas de incubación, el pasto de 30 días de edad, respecto el de 60 días, presentó mayor DMS (68.97 vs. $65.30 \%)$, menor producción de gas (463.56 vs. $499.27 \mathrm{ml}$ ) y de $\mathrm{CH}_{4}$ (101.37 vs. $109.97 \mathrm{ml}$ ) por gramo de $\mathrm{MS}_{\mathrm{d}}$ y menor producción de $\mathrm{CH}_{4}$ como porcentaje de la ED incubada (22.83 vs. $24.70 \%$ ).

La relación $F / S$ afectó significativamente $(p<0.05)$ todas las variables analizadas. En el intervalo entre 0 y 48 horas de incubación el factor relación $\mathrm{F} / \mathrm{S}$ presentó un comportamiento creciente en las medias conforme se redujo la participación de forraje y se aumentó la de suplemento. La producción media de $\mathrm{CH}_{4}$ en este intervalo (con independencia de la edad del pasto) fue 57.40, 73.70 y $81.85 \mathrm{ml}$ (por cada gramo de $\mathrm{MS}_{\mathrm{i}}$ ) y $96.15,107.15$ y $113.70 \mathrm{ml}$ (por cada gramo de $\mathrm{MS}_{\mathrm{d}}$ ) para relaciones F/S de 100/0, $75 / 25$ y $50 / 50$, respectivamente. Para estas mismas proporciones, la producción media de $\mathrm{CH}_{4}$ correspondió a $12.50,16.50$ y $18.80 \%$ de la EB incubada y, $21.30,23.80$ y $26.20 \%$ de la ED incubada, respectivamente. Al término de la incubación la DMS fue $60.55,68.85$ y $72.00 \%$ para las relaciones $F / S 100 / 0,75 / 25$ y $50 / 50$, respectivamente. El comportamiento expresado por estas variables también se observó cuando se contrastaron las medias correspondientes a las diferentes proporciones $\mathrm{F} / \mathrm{S}$ al interior del factor edad del pasto (pasto de la misma edad).

En la tabla 5 se observa que la edad del pasto afectó significativamente $(p<0.05)$ la concentración de acético, propiónico y butírico,

Table 3. Cumulative gas production (hours post-incubation) and dry matter digestibility of mixtures between 30 or 60 days old Kikuyu grass (Pennisetum clandestinum) with concentrate for three forage: concentrate proportions. Values in parentheses are standard deviations.

\begin{tabular}{|c|c|c|c|c|c|c|c|}
\hline \multirow{2}{*}{ Variable } & \multirow{2}{*}{$\begin{array}{l}\text { Interval } \\
\text { (hours) }\end{array}$} & \multicolumn{3}{|c|}{ K30 } & \multicolumn{3}{|c|}{ K60 } \\
\hline & & $100 / 0$ & $75 / 25$ & $50 / 50$ & $100 / 0$ & $75 / 25$ & $50 / 50$ \\
\hline \multirow[t]{4}{*}{ Gas production (ml/g $\mathrm{DM})$} & $0-6$ & $48.7(2.3)^{\mathrm{b}}$ & $61.4(4.8)^{\mathrm{a}}$ & $69.5(2.5)^{a}$ & $52.9(1.6)^{\mathrm{b}}$ & $64.3(1.4)^{\mathrm{ab}}$ & $71.1(4.1)^{\mathrm{a}}$ \\
\hline & $0-12$ & $104.9(8.2)^{c}$ & $126.1(8.9)^{b}$ & $151.8(6.5)^{\mathrm{a}}$ & $99.7(2.4)^{c}$ & $123.7(4.1)^{\mathrm{b}}$ & $145.9(3.2)^{\mathrm{a}}$ \\
\hline & $0-24$ & $197.8(10.9)^{\mathrm{c}}$ & $240.1(5.7)^{\mathrm{b}}$ & $275.4(10)^{a}$ & $188.4(8.1)^{c}$ & $232.1(5)^{b}$ & $269.1(5.5)^{\mathrm{a}}$ \\
\hline & $0-48$ & $281(14)^{c}$ & $325(2.1)^{\mathrm{b}}$ & $354.3(6)^{\mathrm{a}}$ & $283(17.4)^{c}$ & $332.2(9.8)^{b}$ & $358.2(3.3)^{\mathrm{a}}$ \\
\hline \multirow[t]{4}{*}{ Dry matter digestibility (\%) } & $0-6$ & $20.5(0.6)$ & $23.0(5.4)$ & $25.6(2,8)$ & $20,3(1,5)$ & $20,9(2.3)$ & $25.7(5.6)$ \\
\hline & $0-12$ & $30.8(1.7)^{\mathrm{bA}}$ & $35,9(1.8)^{\mathrm{ab}}$ & $40.1(1.4)^{a}$ & $25(0.4)^{\mathrm{bB}}$ & $31.4(2.4)^{\mathrm{a}}$ & $35.9(2.5)^{\mathrm{a}}$ \\
\hline & $0-24$ & $52.4(5.9)^{\mathrm{bA}}$ & $61.6(4.9)^{\mathrm{aA}}$ & $66(3.9)^{a}$ & $42.2(2.8)^{\mathrm{CB}}$ & $52.5(1.3)^{\mathrm{bB}}$ & $61.9(1.7)^{\mathrm{a}}$ \\
\hline & $0-48$ & $65.9(0.5)^{\mathrm{bA}}$ & $69.1(3.2)^{\mathrm{ab}}$ & $71.9(3.7)^{a}$ & $55.2(7.2)^{\mathrm{bB}}$ & $68.6(1.2)^{\mathrm{a}}$ & $72.1(1.7)^{\mathrm{a}}$ \\
\hline \multirow[t]{4}{*}{ Gas production $\left(\mathrm{ml} / \mathrm{g}_{\mathrm{d}} \mathrm{DM}\right)$} & $0-6$ & $237.7(18.1)$ & $275.3(54.6)$ & $273.5(29.2)$ & $261.0(12)$ & $309.4(30.3)$ & $288.1(78.1)$ \\
\hline & $0-12$ & $342.4(46.3)^{\mathrm{B}}$ & $351.9(34.3)$ & $379.6(26.6)$ & $398.4(15)^{A}$ & $394.9(23.2)$ & $408.0(33.9)$ \\
\hline & $0-24$ & $380.7(48.8)^{B}$ & $390.9(22.5)$ & $417.6(14.4)$ & $447.4(19.5)^{A}$ & $442.5(20.4)$ & $434.5(9.6)$ \\
\hline & $0-48$ & $426.1(21.6)^{\mathrm{bB}}$ & $471.1(20.6)^{a}$ & $493.5(21)^{a}$ & $516.5(39.1)^{A}$ & $484.4(21.2)$ & $496.9(16.1)$ \\
\hline
\end{tabular}

abc, lowercase letters in the same row indicate significant difference between means of different $F / S$ ratio for a same grass age ( $p<0.05$ ). $A B$, capital letters in the same row indicate significant difference between grass age means for the same $F / S$ ratio $(p<0.05)$.

$\mathrm{D} \mathrm{DM}=$ incubated dry matter; ${ }_{\mathrm{d}} \mathrm{DM}=$ digestible dry matter. 
Table 4. Cumulative production of methane (hours post-incubation) from mixtures of 30 and 60 days old Kikuyu grass (Pennisetum clandestinum) with concentrate supplement in three forage/supplement proportions. Values in parentheses are standard deviations.

\begin{tabular}{|c|c|c|c|c|c|c|c|}
\hline \multirow{2}{*}{ Variable } & \multirow{2}{*}{$\begin{array}{l}\text { Interval } \\
\text { (hours) }\end{array}$} & \multicolumn{3}{|c|}{ K30 } & \multicolumn{3}{|c|}{ K60 } \\
\hline & & $100 / 0$ & $75 / 25$ & $50 / 50$ & $100 / 0$ & $75 / 25$ & $50 / 50$ \\
\hline \multirow[t]{4}{*}{$\mathrm{CH}_{4}$ Production $\left(\mathrm{ml} / \mathrm{g} \mathrm{DM} \mathrm{i}_{\mathrm{i}}\right)$} & $0-6$ & $5.6(0.5)^{b}$ & $8.3(1.1)^{\mathrm{ab}}$ & $10.4(0.4)^{\mathrm{a}}$ & $7.0(1.6)^{b}$ & $10.1(1.3)^{\mathrm{ab}}$ & $11.4(1.8)^{\mathrm{a}}$ \\
\hline & $0-12$ & $18.9(2.3)^{\mathrm{b}}$ & $25.4(1.2)^{\mathrm{a}}$ & $29.0(3.3)^{\mathrm{a}}$ & $17.0(1.8)^{c}$ & $25.9(1.2)^{\mathrm{b}}$ & $32.1(2.6)^{a}$ \\
\hline & $0-24$ & $41.1(1.9)^{c}$ & $53.9(1.3)^{\mathrm{b}}$ & $60.4(2.8)^{\mathrm{aB}}$ & $40.2(3.4)^{c}$ & $54.3(1.8)^{\mathrm{b}}$ & $65.6(2.4)^{\mathrm{aA}}$ \\
\hline & $0-48$ & $57.8(2.8)^{c}$ & $73.2(1.6)^{\mathrm{b}}$ & $79.2(3.2)^{\mathrm{a}}$ & $57.0(3.5)^{c}$ & $74.2(2)^{\mathrm{b}}$ & $84.5(4.6)^{\mathrm{a}}$ \\
\hline \multirow[t]{4}{*}{$\mathrm{CH}_{4}$ production $\left(\mathrm{ml} / \mathrm{g}_{\mathrm{d}} \mathrm{DM}\right)$} & $0-6$ & $27.5(1.5)^{\mathrm{b}}$ & $36.6(3.3)^{\mathrm{ab}}$ & $40.9(3.7)^{\mathrm{a}}$ & $34.0(5.9)^{\mathrm{b}}$ & $48.7(7.2)^{a}$ & $46.2(13.8)^{\mathrm{ab}}$ \\
\hline & $0-12$ & $61.9(11.2)$ & $71.0(6.6)$ & $72.2(7.3)^{\mathrm{B}}$ & $68.0(8)^{b}$ & $82.6(2.5)^{a}$ & $89.5(7.6)^{\mathrm{aA}}$ \\
\hline & $0-24$ & $79.2(9.9)^{\mathrm{B}}$ & $87.8(5.4)^{\mathrm{B}}$ & $91.8(8.1)^{\mathrm{B}}$ & $95.3(4.9)^{\mathrm{A}}$ & $103.5(5.6)^{\mathrm{A}}$ & $105.9(5.2)^{A}$ \\
\hline & $0-48$ & $87.6(4.6)^{\mathrm{bB}}$ & $106.2(6.6)^{\mathrm{a}}$ & $110.3(7.9)^{\mathrm{a}}$ & $104.7(17.6)^{A}$ & $108.1(3.7)$ & $117.1(6.3)$ \\
\hline \multirow[t]{4}{*}{ GE transformed into $\mathrm{CH}_{4}(\%)$} & $0-6$ & $1.2(0.1)^{\mathrm{b}}$ & $1.9(0.3)^{\mathrm{ab}}$ & $2.4(0.1)^{\mathrm{a}}$ & $1.5(0.4)^{b}$ & $2.3(0.3)^{\mathrm{ab}}$ & $2.6(0.4)^{\mathrm{a}}$ \\
\hline & $0-12$ & $4.1(0.5)^{c}$ & $5.7(0.3)^{\mathrm{b}}$ & $6.7(0.8)^{\mathrm{a}}$ & $3.7(0.4)^{c}$ & $5.8(0.3)^{b}$ & $7.4(0.6)^{\mathrm{a}}$ \\
\hline & $0-24$ & $8.9(0.4)^{c}$ & $12.0(0.3)^{\mathrm{b}}$ & $13.9(0.6)^{\mathrm{aB}}$ & $8.8(0.7)^{c}$ & $12.2(0.4)^{\mathrm{b}}$ & $15.1(0.6)^{\mathrm{aA}}$ \\
\hline & $0-48$ & $12.6(0.6)^{c}$ & $16.4(0.4)^{\mathrm{b}}$ & $18.2(0.7)^{\mathrm{aB}}$ & $12.4(0.8)^{c}$ & $16.6(0.4)^{b}$ & $19.4(1.1)^{\mathrm{aA}}$ \\
\hline \multirow[t]{4}{*}{$\mathrm{DE}$ transformed into $\mathrm{CH}_{4}(\%)$} & $0-6$ & $5.8(0.3)$ & $8.2(0.9)$ & $9.7(0.8)$ & $7.4(1.1)$ & $11.1(2)$ & $10.5(2.8)$ \\
\hline & $0-12$ & $13.3(2.9)$ & $16.0(1.7)$ & $13.2(5.9)^{\mathrm{B}}$ & $15(2)^{b}$ & $17.8(0.3)^{\mathrm{ab}}$ & $20.6(2.6)^{\mathrm{aA}}$ \\
\hline & $0-24$ & $17.5(2.5)^{\mathrm{b}}$ & $19.9(1.6)^{\mathrm{ab}}$ & $22.1(3.2)^{\mathrm{a}}$ & $20.6(1.7)$ & $23.0(1.6)$ & $23.8(0.8)$ \\
\hline & $0-48$ & $19.7(0.9)^{\mathrm{b}}$ & $23.5(0.9)^{a b}$ & $25.3(1.9)^{\mathrm{a}}$ & $22.9(4.8)^{b}$ & $24.1(1.4)^{\mathrm{ab}}$ & $27.1(1.9)^{\mathrm{a}}$ \\
\hline
\end{tabular}

abc, lowercase letters in the same row indicate significant difference between means of different $F / S$ ratios for a same grass age ( $p<0.05$ ).

$A B$, capital letters in the same row indicate significant difference between grass age means for the same $F / S$ ratio $(p<0.05)$.

${ }_{\mathrm{i}} \mathrm{DM}=$ incubated dry matter; ${ }_{\mathrm{d}} \mathrm{DM}=$ digestible dry matter; $\mathrm{GE}=$ incubated gross energy; $\mathrm{DE}=$ incubated digestible energy.

$\mathrm{CH}_{4}$ production in this time frame, regardless of grass age, was $57.40,73.70$, and $81.85 \mathrm{ml}$ (per gram of $\left.{ }_{i} \mathrm{DM}\right)$ and $96.15,107.15$ and $113.70 \mathrm{ml}$ (per gram of ${ }_{\mathrm{d}} \mathrm{DM}$ ) for $100 / 0,75 / 25$, and 50/50 F/C ratios, respectively. For the same ratios, the average $\mathrm{CH}_{4}$ production corresponded to $12.50,16.50$ and $18.80 \%$ of the $\mathrm{GE}$, and $21.30,23.80$ and $26.20 \%$ of the $\mathrm{DE}$, respectively. After incubation, $\mathrm{DMD}$ was $60.55,68.85$ and $72.00 \%$ for $100 / 0,75 / 25$ and $50 / 50 \mathrm{~F} / \mathrm{C}$ ratios, respectively. Results behaved in a similar way when the means of different $F / C$ rates were compared inside each grass age.

Table 5 shows that grass age significantly affected $(p<0.05)$ acetic, propionic and butyric acid concentration, with the highest values for the young (30 days) compared with the 60 days old grass $(117.87,36.83$ and 23.60 vs. $104.67,33.40$ and $22.47 \mathrm{mmol} / \mathrm{L}$, respectively). The $\mathrm{F} / \mathrm{C}$ ratio had no statistical effect on VFA concentration or the acetate/ propionate ratio $(A / P)(p>0.05)$, but it significantly affected $\mathrm{pH}(\mathrm{p}<0.05)$. Treatments including more concentrate had lower $\mathrm{pH}$ values (6.50 and 6.52 for $50 / 50$ and $75 / 25$ ratios, respectively, compared with 6.58 for the $100 / 0$ ratio). The grass age*F/C interaction was not significant $(p>0.05)$ for the variables presented in tables 3,4 and 5 .

\section{DISCUSSION}

Effect of grass age on production of gas, $\mathbf{C H}_{4}$, and DMD. Caro and Correa (15) reported a $7.8 \%$ increase in NDF and $2.7 \%$ reduction con valores más altos para el pasto de 30 días de edad, $117.87,36.83$ y $23.60 \mathrm{mmol} / \mathrm{L}$, respectivamente, comparado con el pasto de 60 días, $104.67,33.40$ y $22.47 \mathrm{mmol} / \mathrm{L}$, respectivamente. La relación $\mathrm{F} / \mathrm{S}$ no tuvo efecto estadístico $(p>0.05)$ sobre la concentración de AGV y la relación acetato/propionato $(A / P)$, pero sí afectó significativamente el $\mathrm{pH}(\mathrm{p}<0.05)$. Se observó que los tratamientos con mayor adición de suplemento presentaron menores valores de $\mathrm{pH}, 6.50$ y 6.52 para relaciones $50 / 50$ y $75 / 25$, respectivamente, en contraste con 6.58 para la relación 100/0. Para las variables que se presentan en las tablas 3, 4 y 5, la interacción E*F/S no fue significativa $(p>0.05)$.

\section{DISCUSIÓN}

Efecto de la edad del pasto sobre la DMS y la producción de gas y de $\mathbf{C H}_{4}$. Caro y Correa (15) reportaron un incremento de $7.8 \%$ en la concentración de FDN y una reducción de $2.7 \%$ en el contenido de CNE cuando compararon pasto kikuyo cosechado a los 32 y 58 días de rebrote. En el pasto del presente estudio, el aumento en la concentración de FDN y la reducción en el contenido de CNE superó el reporte de los autores (Tabla 1). Es de esperarse que la calidad de los forrajes disminuya con la madurez, lo cual fue verificado por Caro y Correa (15), quienes encontraron que los cambios en la composición química afectaron la digestibilidad in situ a las $24 \mathrm{~h}$ de incubación; siendo $6.7 \%$ más alta para el pasto 
Table 5. Fermentation profile and pH from mixtures of 30 and 60 days old Kikuyu grass (Pennisetum clandestinum) with concentrate supplement in three forage/supplement proportions. Values in parentheses are standard deviations.

\begin{tabular}{|c|c|c|c|c|c|c|c|}
\hline & \multirow{2}{*}{$\begin{array}{c}\text { Interval } \\
\text { (hours) }\end{array}$} & \multicolumn{3}{|c|}{ K30 } & \multicolumn{3}{|c|}{ K60 } \\
\hline & & $100 / 0$ & $75 / 25$ & $50 / 50$ & $100 / 0$ & $75 / 25$ & $50 / 50$ \\
\hline \multirow[t]{4}{*}{ Acetate $(\mathrm{mmol} / \mathrm{L})$} & $0-6$ & $110.7(7)^{A}$ & $94.9(6.2)$ & $102.8(12.7)^{A}$ & $86.6(14.9)^{\mathrm{B}}$ & $92.7(4.6)$ & $76.5(14.9)^{\mathrm{B}}$ \\
\hline & $0-12$ & $102.1(4.6)$ & $99.8(7.1)$ & $86.7(15.6)$ & $84.2(25.7)$ & $79.0(16.2)$ & $87.2(6.4)$ \\
\hline & $0-24$ & $96.6(13)$ & $90.6(27.6)$ & $108.8(14.5)$ & $92.7(9.8)$ & $83.2(20.4)$ & $98.2(10)$ \\
\hline & $0-48$ & $121.1(6)$ & $101.8(21.3)$ & $120.7(20.4)$ & $108.2(17.1)$ & $107.4(7.7)$ & $98.4(8)$ \\
\hline \multirow[t]{4}{*}{ Propionate $(\mathrm{mmol} / \mathrm{L})$} & $0-6$ & $33.4(0.5)$ & $31(1.8)$ & $32.1(2.9)^{A}$ & $29.7(3.7)$ & $29.0(0.2)$ & $27.5(3.1)^{\mathrm{B}}$ \\
\hline & $0-12$ & $32.8(0.5)$ & $32.6(1.5)^{A}$ & $30.1(3.5)$ & $28.6(4.2)$ & $27.2(1.8)^{\mathrm{B}}$ & $29.1(1.4)$ \\
\hline & $0-24$ & $32.6(2.2)$ & $32.0(4.7)$ & $35.5(2.8)$ & $30.7(2.1)$ & $29.2(3)$ & 33.1 (1.9) \\
\hline & $0-48$ & $39.2(0.6)^{A}$ & $33.7(4)$ & $37.6(3.8)^{\mathrm{A}}$ & $34.3(3.8)^{\mathrm{B}}$ & $32.9(1.7)$ & $33(0.7)^{\mathrm{B}}$ \\
\hline \multirow[t]{4}{*}{ Butyrate (mmol/L) } & $0-6$ & $22.1(0.5)$ & $21.0(0.9)$ & $22.3(1.5)^{\mathrm{A}}$ & $20.9(2.4)$ & $20.9(0.1)$ & $19.6(1.5)^{\mathrm{B}}$ \\
\hline & $0-12$ & $22.6(0.8)$ & $22.3(0.4)^{A}$ & $20.0(1)$ & $20.3(2.5)$ & $19.8(1.2)^{\mathrm{B}}$ & $20.6(1)$ \\
\hline & $0-24$ & $21.6(2.2)$ & $22.3(2.7)$ & $23.5(1.3)$ & $20.4(1.1)$ & $20.6(1.6)$ & $22.9(1.5)$ \\
\hline & $0-48$ & $23.1(0.5)$ & $22.0(1.4)$ & $25.7(1.9)^{\mathrm{A}}$ & $22.2(1.7)$ & $22.3(0.7)$ & $22.9(0.8)^{\mathrm{B}}$ \\
\hline \multirow{4}{*}{ Acetate/Propionate } & $0-6$ & $3.3(0.2)$ & $3.1(0)$ & $3.2(0.1)$ & $2.9(0.1)$ & $3.2(0.1)$ & $2.8(0.2)$ \\
\hline & $0-12$ & $3.1(0.1)$ & $3.1(0.2)$ & $2.9(0.2)$ & $2.9(0.6)$ & $2.9(0.4)$ & $3.0(0.1)$ \\
\hline & $0-24$ & $3.0(0.2)$ & $2.8(0.5)$ & $3.1(0.2)$ & $3.0(0.2)$ & $2.8(0.4)$ & $3.0(0.2)$ \\
\hline & $0-48$ & $3.3(0.1)$ & $3.0(0.3)$ & $3.2(0.2)$ & $3.1(0.2)$ & $3.3(0.1)$ & $3.0(0.2)$ \\
\hline \multirow[t]{4}{*}{$\mathrm{pH}$} & $0-6$ & $7.04(0.03)$ & $7(0.04)$ & $7.02(0.05)^{A}$ & $6.99(0.02)$ & $6.99(0.04)$ & $6.95(0.08)^{\mathrm{B}}$ \\
\hline & $0-12$ & $6.75(0.02)^{\mathrm{a}}$ & $6.71(0.03)^{\mathrm{ab}}$ & $6.67(0.02)^{\mathrm{b}}$ & $6.75(0.03)^{\mathrm{a}}$ & $6.72(0.02)^{\mathrm{ab}}$ & $6.67(0.02)^{b}$ \\
\hline & $0-24$ & $6.67(0.06)^{a}$ & $6.58(0.01)^{\mathrm{b}}$ & $6.53(0.01)^{\mathrm{b}}$ & $6.64(0.03)^{\mathrm{a}}$ & $6.57(0.03)^{\mathrm{b}}$ & $6.52(0.03)^{b}$ \\
\hline & $0-48$ & $6.59(0.02)^{\mathrm{a}}$ & $6.54(0.02)^{\mathrm{ab}}$ & $6.51(0.02)^{\mathrm{b}}$ & $6.57(0.03)^{\mathrm{a}}$ & $6.5(0.01)^{b}$ & $6.48(0.01)^{b}$ \\
\hline
\end{tabular}

$a b c$, lowercase letters in the same row indicate significant difference between means of different $F / S$ ratios for a same grass age ( $p<0.05$ ). $A B$, capital letters in the same row indicate significant difference between grass age means for the same $F / S$ ratio $(p<0.05)$.

in NSC for Kikuyu grass harvested at 32 vs. 58 days of regrowth. In the present study, NDF increase and NSC reduction exceeded the figures reported by those researchers (Table 1). It is expected that forage quality decrease with maturity, which was verified by Caro and Correa (15), who found that changes in the chemical composition affect in situ digestibility at $24 \mathrm{~h}$ incubation. They reported a $6.7 \%$ increase in grass digestibility after 32 days of regrowth compared to 58 days. This is in agreement with the present study, where DMD at 24 hours of incubation was higher for the younger grass (Table 3 ). Within species, increased harvest age is associated with higher NDF, ADF and ADL levels, and lower CP content (Table 1 ) as well as DMD reduction.

Chaves et al (16) concluded that $\mathrm{CH}_{4}$ produced by grazing heifers was significantly affected by the type of grass, reflecting differences in maturity and chemical composition and confirming that $\mathrm{CH}_{4}$ production is primarily a function of the amount of cell wall digested in the rumen. In the present study, pasture age significantly affected gas and $\mathrm{CH}_{4}$ production (per gram of ${ }_{d} \mathrm{DM}$ ) and $\mathrm{CH}_{4}$ (as percent of DE) (Tables 3 and 4). According to Sun et al (17), $\mathrm{CH}_{4}$ production should be expressed in relation to ${ }_{d} D M$, instead of $D M$. They reported that Cichorium intybus and Lolium perenne fodder had similar $\mathrm{CH}_{4}$ production on $\mathrm{DM}$ basis despite their differences in NDF (28.1 de 32 días de rebrote en comparación con el de 58 días. Los resultados del presente trabajo confirman los hallazgos de los autores, toda vez que a las 24 horas de incubación la DMS fue superior para el pasto de menor edad (Tabla 3). Dentro de una misma especie, el aumento en la edad de cosecha se asocia con mayor contenido de FDN, FDA y LDA, menor contenido de PB (Tabla 1 ) y reducción en la DMS.

Chaves et al (16) concluyeron que la producción de $\mathrm{CH}_{4}$ de novillas en pastoreo fue afectada significativamente por el tipo de pasto, como reflejo de las diferencias en madurez y composición química de los forrajes analizados, confirmando el concepto que la producción de $\mathrm{CH}_{4}$ es, principalmente, una función de la cantidad de pared celular digerida en el rumen. En el presente trabajo, la edad del pasto afectó significativamente la producción de gas y de $\mathrm{CH}_{4}$ cuando estas variables fueron expresadas por gramo de $\mathrm{MS}_{\mathrm{d}}$ y el $\mathrm{CH}_{4}$ como porcentaje de la ED (Tabla 3 y 4). La importancia de expresar la producción de $\mathrm{CH}_{4}$ en relación con la $\mathrm{MS}_{\mathrm{d}}$ y no con la $\mathrm{MS}_{\mathrm{i}}$, se confirmó en el trabajo de Sun et al (17), quienes reportaron que los forrajes Cichorium intybus y Lolium perenne tuvieron similar producción de $\mathrm{CH}_{4}$ en función de la $\mathrm{MS}_{\text {, }}$ a pesar de sus diferencias en el contendido de FDN, 28.1 y $49.9 \%$ respectivamente, y la mayor digestibilidad del primero. En el presente trabajo, el tratamiento K30-100/0 tuvo menor FDN, FDA y LDA (Tabla 2), mayor digestibilidad acumulada a las 48 horas $(p<0.05)$, e igual producción de gas y $\mathrm{CH}_{4}$ por 
and $49.9 \%$, respectively) and the higher digestibility of Cichorium intybus. In the present study, treatment $\mathrm{K} 30-100 / 0$ resulted in lower NDF, ADF and ADL (Table 2), higher accumulated digestibility at 48 hours $(p<0.05)$, and similar gas and $\mathrm{CH}_{4}$ production (per gram of DM) compared to treatment K60-100/0. However, when gas production and $\mathrm{CH}_{4}$ were expressed per gram of DM (Tables 3 and 4) the values were statistically higher for the older grass (60 days) $(p<0.05)$. Accordingly, highly digestible forage can produce the same gas and $\mathrm{CH}_{4}$ per gram of $\mathrm{DM}$; which switches when production of both is expressed as per gram of ${ }_{d} \mathrm{DM}$. The higher digestibility of the substrate mathematically reduces gas and $\mathrm{CH}_{4}$ production and biologically increases $\mathrm{Y}_{\text {ATP }}$. Van Soest et al (18) defined microbial efficiency as the proportion of the substrate energy fixed by the cells and, thus, it is inversely related to VFA and $\mathrm{CH}_{4}$ production.

Effect of $\mathrm{F} / \mathrm{C}$ ratio on DMD, $\mathrm{CH}_{4}$ and gas production. The increase in gas production and $\mathrm{CH}_{4}$ per gram of DM observed with decreasing $F / C$ ratios (Tables 3 and 4 ) can be attributed to higher NSC vs. NDF in the incubated substrate (Table 2). The high NSC proportion in the concentrate supplement (Table 1) explains its upward trend as F/C decreased, resulting in a higher NSC/NDF ratio (Table 2). Pellikaan et al (19) also found increased in vitro $\mathrm{CH}_{4}$ and gas production from substrates with low NDF and high starch content. They obtained 399.9 and $66.8 \mathrm{ml}$ for gas and $\mathrm{CH}_{4}$, respectively, from potato starch (per gram of incubated organic matter); while values were 273.3 and 47.6 $\mathrm{ml}$, respectively, from grass silage. NavarroVilla et al (11) also reported increased production of gas and $\mathrm{CH}_{4}$ for incubated barley grain compared with barley straw and grass silage. In the present study, the increased gas and $\mathrm{CH}_{4}$ production from substrates with concentrate supplement can be explained by their higher DMD (Table 3 ). However, it is important to note that this increased digestibility was not sufficient to generate a downward trend in gas and $\mathrm{CH}_{4}$ output (at 48 hours of incubation) as $\mathrm{F} / \mathrm{C}$ decreased when they were expressed as per gram of ${ }_{d} D M$. The only exception to this was gas production per gram of ${ }_{d} D M$ from grass harvested at 60 days (Tables 3 and 4). Lower levels of incubated protein as F/C decreased -especially for 30 days grass- may be associated with reductions in $\mathrm{CH}_{4}$. According Inthapanya and Preston (20), less protein degradation in the incubated substrate decreases $\mathrm{CH}_{4}$ production. However, this gramo de $\mathrm{MS}_{\mathrm{i}}$ que el tratamiento $\mathrm{K} 60-100 / 0$. No obstante, cuando la producción de gas y de $\mathrm{CH}_{4}$ fue expresada por gramo de $\mathrm{MS}_{\mathrm{d}}$ (Tabla 3 y 4 ), los valores fueron estadísticamente mayores para el pasto de 60 días de edad $(p<0.05)$. Lo anterior confirma que un forraje de mayor digestibilidad puede producir igual gas y $\mathrm{CH}_{4}$ por gramo de $\mathrm{MS}_{\mathrm{i}}$, efecto que se revierte cuando la producción de ambos se expresa por gramo de $\mathrm{MS}_{\mathrm{d}}$. La mayor digestibilidad del sustrato matemáticamente reduce la producción de gas y de $\mathrm{CH}_{4}$ y, biológicamente aumenta el $Y_{\text {ATP. }}$. Van Soest et al (18) definieron la eficiencia microbiana como la proporción de energía contenida en el sustrato que es fijada en las células y, por tanto, está inversamente relacionada con la producción de $\mathrm{AGV}$ y de $\mathrm{CH}_{4}$.

Efecto de la relación $\mathrm{F} / \mathrm{S}$ sobre la DMS y la producción de gas y de $\mathbf{C H}_{4}$. El incremento en la producción de gas y de $\mathrm{CH}_{4}$ por gramo de $\mathrm{MS}_{4}$ que se observó con la disminución de la relación F/S (Tablas 3 y 4) puede atribuirse a la mayor concentración de CNE respecto la FDN en el sustrato incubado (Tabla 2). La alta proporción de CNE en el suplemento (Tabla 1) explicó el comportamiento creciente que este nutriente registró a medida que disminuyó la relación $\mathrm{F} / \mathrm{S}$, conllevando a una mayor relación CNE/FDN (Tabla 2). Pellikaan et al (19) también encontraron mayor producción de gas y de $\mathrm{CH}_{4}$ in vitro en sustratos con menor contenido de FDN y mayor contenido de almidones. Para el almidón de papa, los autores reportaron producciones de gas y de $\mathrm{CH}_{4}$, por gramo de materia orgánica incubada, de 399.9 y $66.8 \mathrm{ml}$, respectivamente, mientras para el ensilaje de pasto los valores fueron 273.3 y 47.6 $\mathrm{ml}$, correspondientemente. Navarro-Villa et al (11) igualmente evidenciaron mayor producción de gas y de $\mathrm{CH}_{4}$ cuando incubaron grano de cebada, respecto a paja de cebada y ensilaje de pasto.

En el presente estudio, la mayor producción de gas y de $\mathrm{CH}_{4}$ en los sustratos que incluyeron suplemento puede ser explicada por su mayor DMS (Tabla 3). Sin embargo, es importante señalar que esta mayor digestibilidad no fue suficiente para generar una tendencia decreciente en los resultados de producción de gas y de $\mathrm{CH}_{4}$ (a las 48 horas de incubación), cuando estas variables fueron expresadas por gramo de $\mathrm{MS}_{\mathrm{d}}$ conforme disminuyó la relación F/S. La única excepción a este comportamiento se observó para la producción de gas por gramo de $\mathrm{MS}_{\mathrm{d}}$ en el pasto cosechado a los 60 días de edad (Tablas 3 y 4). Los menores niveles de proteína incubada conforme se redujo la relación $\mathrm{F} / \mathrm{S}$, especialmente en los tratamientos que incluyeron el pasto kikuyo de 30 días de edad, pueden estar asociados con reducción en la producción de $\mathrm{CH}_{4}$. De acuerdo con los hallazgos de Inthapanya y Preston (20), una menor degradación de la proteína en el sustrato incubado reduce 
effect was smaller in the present study compared to that generated by a higher NSC/ NDF ratio, as previously stated.

Increased in vitro $\mathrm{CH}_{4}$ production per gram of $D M$ and $D M$ in treatments with low $\mathrm{F} / \mathrm{C}$ (Table 4 ) is not in agreement with in vivo results (21), where it is accepted that rapidly fermenting diets decrease $\mathrm{CH}_{4}$ production. The effect of these diets on in vivo $\mathrm{CH}_{4}$ production is explained by a decrease in ruminal $\mathrm{pH}$, affecting the growth of methanogens, protozoa (22) and cellulolytic bacteria (23), and increasing passage rate, which reduces the number of protozoa and thus interspecies transfer of $\mathrm{H}_{2}$ and methanogenesis (24). The in vitro gas technique does not allow replacing the liquid and/or solid fractions, and a buffer solution is added to guarantee $\mathrm{pH}$ stability between 6.5 to 7.0 (Table 5). Both things may explain the divergence between in vitro and in vivo results regarding $\mathrm{CH}_{4}$ for increasing NSC levels. This was reported by Navarro-Villa et al (11), who measured $70 \%$ higher $\mathrm{CH}_{4}$ for grains compared with forages incubated in vitro, while McGeough et al (25) reported lower $\mathrm{CH}_{4}$ production from ruminants fed cereal based diets.

The $\mathrm{CH}_{4}$ increase, as a percentage of the $\mathrm{GE}$ and $\mathrm{DE}$, is consistent with $\mathrm{CH}_{4}$ emissions per gram of $\mathrm{DM}$ and ${ }_{\mathrm{d}} \mathrm{DM}$ (Table 4 ). Values ranged from 8.8 (K60-100/0) and 15.1\% (K60$50 / 50)$ of GE after 24 hours of incubation, surpassing the results by Bhatta et al (26) who evaluated mixed diets also at 24 hours of incubation and obtained between 4.4 and $7.8 \%$ of $\mathrm{GE}$.

Effect of grass age on fermentation profile. Glucose is a common intermediary among carbohydrates degraded in the rumen and their final products (VFA, $\mathrm{CO}_{2}$ and $\mathrm{CH}_{4}$ ). The mechanism that controls glucose partition between different VFA depends on food composition (2). Tropical grasses usually grow and mature faster, rapidly turning into fibrous and less digestible. The lower NDF content (Table 2) and the larger DMD (Table 3 ) of 30-day grass treatments is consistent with the higher VFA concentration, as reported in Table 5, explaining the significant effect of age on acetate, propionate and butyrate production $(p<0.05)$. la producción de este gas. En este trabajo, no obstante, este efecto fue menor frente al generado por la mayor relación CNE/FDN, como previamente fue indicado.

La mayor producción in vitro de $\mathrm{CH}_{4}$, por gramo de $\mathrm{MS}_{\text {y }} \mathrm{MS}_{\mathrm{d}}$ en los tratamientos con menor relación F/S (Tabla 4) no es consistente con los resultados encontrados in vivo (21), donde es aceptado que la utilización de dietas de rápida fermentación reduce la producción de $\mathrm{CH}_{4}$. El efecto de este tipo de dietas sobre la producción in vivo de $\mathrm{CH}_{4}$ se explica por la disminución del $\mathrm{pH}$ ruminal, que afecta el crecimiento de metanógenos, protozoos (22) y bacterias celulolíticas (23), y por el aumento en la tasa de pasaje, que reduce el número de protozoarios y con ello la transferencia interespecie de $\mathrm{H}_{2}$ y la metanogénesis (24). En la técnica in vitro de producción de gas, metodología empleada en este trabajo, no es posible el recambio de la fracción líquida y/o sólida y se incluye una solución buffer que garantiza la estabilidad del $\mathrm{pH}$ en un rango entre 6.5 a 7.0 (Tabla 5). Ambos conceptos posiblemente expliquen la divergencia entre la producción de $\mathrm{CH}_{4}$ in vitro y los reportes in vivo cuando se evalúan niveles crecientes de CNE en el sustrato fermentado. Esta situación fue reportada por Navarro-Villa et al (11), quienes obtuvieron producciones de $\mathrm{CH}_{4} 70 \%$ mayores para los granos respecto a los forrajes incubados in vitro, en tanto McGeough et al (25) registraron menor producción de $\mathrm{CH}_{4}$ en rumiantes alimentados con dietas basadas en cereales.

El aumento en la producción de $\mathrm{CH}_{4}$, expresado como porcentaje de la EB y ED es consistente con las emisiones de $\mathrm{CH}_{4}$ por gramo de $\mathrm{MS}_{\mathrm{i}}$ y $\mathrm{MS}_{\mathrm{d}}$ (Tabla 4). A las 24 horas de incubación los valores fluctuaron entre $8.8(\mathrm{~K} 60-100 / 0)$ y $15.1 \%(\mathrm{~K} 60-50 / 50)$ de la $\mathrm{EB}_{\mathrm{i}}$, superando el reporte de Bhatta et al (26) evaluando dietas mixtas, entre 4.4 y $7.8 \%$ de la $\mathrm{EB}$, igualmente a las 24 horas de incubación.

Efecto de la edad del pasto sobre el perfil de fermentación. La glucosa es un intermediario común entre los carbohidratos degradados en el rumen y sus productos finales $\left(\mathrm{AGV}, \mathrm{CO}_{2}\right.$ y $\left.\mathrm{CH}_{4}\right)$. El mecanismo que controla la partición de la glucosa entre los diferentes AGV está en función de la composición de los alimentos ingeridos (2). Los pastos tropicales generalmente crecen y maduran rápido, lo cual los convierte en alimentos más fibrosos y menos digestibles en un corto período de tiempo. El menor contenido de FDN (Tabla 2) y la mayor DMS (Tabla 3) para los tratamientos que incluyeron el pasto de 30 días es consistente con la mayor concentración de AGV que se reporta en la tabla 5, explicando el efecto significativo $(p<0.05)$ del factor edad sobre la producción de acetato, propionato y butirato. 
Effect of $F / C$ ratio on fermentation profile. When fiber-rich diets change to diets based on concentrates, a decrease can be expected in ruminal $\mathrm{pH}(27)$, number of fibrolytic bacteria (23) and the $A / P$ ratio (28). Although in the present study $\mathrm{F} / \mathrm{C}$ significantly affected the $\mathrm{pH}$, it tended to remain high and stable due to the $\mathrm{HCO}_{3}{ }^{-} / \mathrm{CO}_{2}$ balance of the buffer solution, which could explain the lack of significant effect of the $\mathrm{F} / \mathrm{C}$ ratio on the $\mathrm{A} / \mathrm{P}$ ratio (Table 5 ). Citric acid has been suggested to overcome the buffer effect and perform in vitro evaluations at $\mathrm{pH}$ lower than 6 (11). However, that strategy did not work in the present study; $\mathrm{pH}$ readings at 6 hours of incubation (Table 5 ) were higher than those recorded at the beginning ( $\mathrm{pH}$ 6.5). This could be explained by citric acid being rapidly fermented by rumen microorganisms to $\mathrm{CO}_{2}$ and acetic acid (29).

The in vitro gas technique does not remove VFA via absorption, so its concentration depends on the fermentation rate. Since DMD increases with incubation time, a higher VFA concentration is expected as fermentation continues. However, this was not observed in this study (Table 5 ). It can be assumed that microorganisms degraded VFA to obtain energy, as observed by Wang et al (30), which would explain the stability of its concentration over the incubation time.

The results of this study confirm that grass age affects DMD, $\mathrm{CH}_{4}$, gas production, and fermentation profile due to a higher proportion of cell wall. A reduction of $F / C$ ratio simultaneous with a high NSC/NDF ratio improves substrate digestibility and increases $\mathrm{CH}_{4}$ and gas production, contradicting the in vivo reports. The $\mathrm{pH}$, which is controlled by the buffer solution, hinders the study of the effect of $\mathrm{F} / \mathrm{C}$ ratio on methanogenesis in in vitro systems. Therefore, for future studies we suggest to change the formulation of the buffer solution to enable the assessments of mixed diets at a $\mathrm{pH}$ close to in vivo.
Efecto de la relación F/S sobre el perfil de fermentación. Cambios en la alimentación, desde dietas altas en fibra a dietas basadas en suplemento concentrado disminuyen el pH ruminal (27), el número de bacterias fibrolíticas (23) y la relación $\mathrm{A} / \mathrm{P}$ (28). Si bien, en el presente trabajo la relación F/S afectó significativamente el $\mathrm{pH}$, los valores tendieron a mantenerse altos y estables gracias al equilibrio $\mathrm{HCO}_{3}{ }^{-} /$ $\mathrm{CO}_{2}$ de la solución buffer, lo que puede explicar la ausencia de efecto estadístico de la relación F/S sobre la relación A/P (Tabla 5). Para superar el efecto de la solución buffer y realizar evaluaciones in vitro a bajo $\mathrm{pH}(<6)$ se ha propuesto la utilización de ácido cítrico (11), no obstante, en el presente trabajo esta estrategia no fue eficiente, y las lecturas de $\mathrm{pH}$ a las 6 horas de incubación (Tabla $5)$ mostraron valores superiores a los registrados al inicio (pH 6.5). Esto pudo deberse a que el ácido cítrico es rápidamente fermentado por los microorganismos ruminales hasta $\mathrm{CO}_{2}$ y ácido acético (29).

En la técnica in vitro de producción de gas no existe remoción de los AGV vía absorción, por lo que su concentración depende de la tasa de fermentación. Dado que la DMS aumenta con el tiempo de incubación, es de esperarse una mayor concentración de AGV a medida que transcurre la fermentación, sin embargo, este comportamiento no fue observado en el presente trabajo (Tabla 5). Es posible suponer que los microorganismos degradaron los AGV para obtener energía, fenómeno observado por Wang et al (30), lo cual estaría explicando la estabilidad en su concentración con el transcurso del tiempo de incubación.

Los resultados del presente experimento corroboran que la edad del pasto afecta la DMS, la producción de gas y de $\mathrm{CH}_{4}$ y el perfil de fermentación debido a su mayor proporción de pared celular. La reducción en la relación $\mathrm{F} / \mathrm{S}$, concomitante con una mayor proporción CNE/FDN, mejora la digestibilidad del sustrato y aumenta la producción de gas y de $\mathrm{CH}_{4}$, esto último contradiciendo los reportes in vivo. El valor de $\mathrm{pH}$, que es controlado por la solución buffer, representa una limitante para estudiar el efecto de la relación F/S sobre la metanogénesis en sistemas in vitro. Por lo tanto, para futuros trabajos se sugiere realizar modificaciones en la formulación de la solución buffer que permitan realizar evaluaciones de dietas mixtas en un $\mathrm{pH}$ cercano al observado in vivo. 


\section{REFERENCES}

1. Kumar S, Puniya AK, Puniya M, Dagar SS, Sirohi SK, Singh $K$ et al. Factors affecting rumen methanogens and methane mitigation strategies. World J Microbiol Biotechnol 2009;25(9):1557-1566.

2. Janssen $\mathrm{PH}$. Influence of hydrogen on rumen methane formation and fermentation balances through microbial growth kinetics and fermentation thermodynamics. Anim Feed Sci Tech 2010; 160(1-2):1-22.

3. Correa HJ, Pabón ML, Carulla JE. Valor nutricional del pasto kikuyo (Pennisetum clandestinum Hoechst Ex Chiov.) para la producción de leche en Colombia (Una revisión): I-Composición química y digestibilidad ruminal y posruminal. Livest Res Rural Dev 2008; 20(4) [en línea] [fecha de acceso 18 de julio de 2014]. URL disponible en: http://www.Irrd.org/ Irrd20/4/corra20059.htm

4. Aguerre MJ, Wattiaux MA, Powell JM, Broderick GA, Arndt C. Effect of forage-to-concentrate ratio in dairy cow diets on emission of methane, carbon dioxide, and ammonia, lactation performance, and manure excretion. J Dairy Sci 2011;94(6):3081-3093.

5. Association of Official Analytical Chemist AOAC. Official Methods of Analysis. 18 ed. Gaithersburg, MD: AOAC Int, 2011.

6. Van Soest PJ, Robertson JB, Lewis BA. Methods for dietary fiber, neutral detergent fiber and nonstarch polysaccharides in relation to animal nutrition. J Dairy Sci 1991; 74(10):3583-3597.

7. Raffrenato E, Van Amburgh ME. Technical note: Improved methodology for analyses of acid detergent fiber and acid detergent lignin. J Dairy Sci 2011; 94(7):3613-3617.

8. Detmann E, Valadares Filho SC. On the estimation of non-fibrous carbohydrates in feeds and diets. Arq Bras Med Vet 2010; 62(4):980-984.

9. Posada SL, Noguera R, Bolívar D. Relación entre presión y volumen para la implementación de la técnica in vitro de producción de gases. Rev Colomb Cienc Pecu 2006; 19(4):407-414.
10. McDougall EI. Studies on ruminant saliva. 1. The composition and output of sheep>s saliva. Biochem J 1948; 43(1):99-109.

11. Navarro-Villa A, O’Brien M, López S, Boland TM, O'Kiely P. Modifications of a gas production technique for assessing in vitro rumen methane production from feedstuffs. Anim Feed Sci Tech 2011; 166-167:163-174.

12. López S, Newbold CJ. Measuring methane production from ruminants. The Netherlands: Springer; 2007.

13. Nkrumah JD, Okine EK, Mathison GW, Schmid K, Li C, Basarab JA et al. Relationships of feedlot feed efficiency, performance, and feeding behavior with metabolic rate, methane production, and energy partitioning in beef cattle. J Anim Sci 2006; 84(1):145-153.

14. SAS/STAT [programa de ordenador]. Versión 9.1.3. Cary (NC): SAS Institute Incorporation; 2003.

15. Caro F, Correa HJ. Digestibilidad posruminal aparente de la materia seca, la proteína cruda y cuatro macrominerales en el pasto kikuyo (Pennisetum clandestinum) cosechado a dos edades de rebrote. Livest Res Rural Dev $2006 ; 18(10)$ [en línea] [fecha de acceso 22 de agosto de 2014].URL disponible en: http:// www.Irrd.org/Irrd18/10/caro18143.htm

16. Chaves AV, Thompson LC, Iwaasa AD, Scott $\mathrm{SL}$, Olson $\mathrm{ME}$, Benchaar $\mathrm{C}$ et al. Effect of pasture type (alfalfa vs. grass) on methane and carbon dioxide production by yearling beef heifers. Can J Anim Sci 2006; 86(3):409-418.

17. Sun XZ, Hoskin SO, Muetzel S, Molano G, Clark $\mathrm{H}$. Effects of forage chicory (Cichorium intybus) and perennial ryegrass (Lolium perenne) on methane emissions in vitro and from sheep. Anim Feed Sci Tech 2011; 166167:391-397.

18. Van Soest PJ, France J, Siddons RC. On the steady-state turnover of compartments in the ruminant gastrointestinal tract. J Theor Biol 1992; 159(2):135-145. 
19. Pellikaan WF, Hendriks WH, Uwimana G, Bongers LJGM, Becker PM, Cone JW. A novel method to determine simultaneously methane production during in vitro gas production using fully automated equipment. Anim Feed Sci Tech 2011; 168(3-4):196-205.

20. Inthapanya S, Preston TR. Methane production from urea-treated rice straw is reduced when the protein supplement is cassava leaf meal or fish meal compared with water spinach meal in a rumen in vitro fermentation. Livest Res Rural Dev 2014; 26(9) [en línea] [fecha de acceso 14 de noviembre de 2014].URL disponible en: http://www.Irrd.org/Irrd26/9/ sang26159.html

21. Doreau M, Van Der Werf HMG, Micol D, Dubroeucq $\mathrm{H}$, Agabriel J, Rochette $\mathrm{Y}$ et al. Enteric methane production and greenhouse gases balance of diets differing in concentrate in the fattening phase of a beef production system. J Anim Sci 2011; 89(8):2518-2528.

22. Hook SE, Steele MA, Northwood KS, Wright $A D, M c B r i d e ~ B W$. Impact of high-concentrate feeding and low ruminal $\mathrm{pH}$ on methanogens and protozoa in the rumen of dairy cows. Microb Ecol 2011; 62(1):94-105.

23. Sung HG, Kobayashi Y, Chang J, Ha A, Hwang IH, Ha JK. Low Ruminal pH Reduces Dietary Fiber Digestion via Reduced Microbial Attachment. Asian-Aust J Anim Sci 2007; 20(2):200-207.

24. Kumar S, Dagar SS, Puniya AK, Upadhyay RC. Changes in methane emission, rumen fermentation in response to diet and microbial interactions. Res Vet Sci 2013; 94(2):263-268.
25. McGeough EJ, O'Kiely P, Foley PA, Hart KJ, Boland TM, Kenny DA. Methane emissions, feed intake, and performance of finishing beef cattle offered maize silages harvested at 4 different stages of maturity. J Anim Sci 2010; 88(4): 1479-1491.

26. Bhatta R, Enishi O, Takusari N, Higuchi K, Nonaka I, Kurihara M. Diet effects on methane production by goats and a comparison between measurement methodologies. J Agr Sci 2008; 146(6):705-715.

27. Bevans DW, Beauchemin KA, SchwartzkopfGenswein KS, McKinnon JJ, McAllister TA. Effect of rapid or gradual grain adaptation on subacute acidosis and feed intake by feedlot cattle. J Anim Sci 2005;83(5):1116-1132.

28. Suárez BJ, Van Reenen CG, Beldman G, van Denle J,Dijkstra J, Gerrits J]. Effects of Supplementing Concentrates Differing in Carbohydrate Composition in Veal Calf Diets: I. Animal Performance and Rumen Fermentation Characteristics. J Dairy Sci 2006; 89(11):4365-4375

29. Wright DE. Citric acid metabolism in the bovine rumen. Applied microbiology 1971; 21(2):165-168.

30. Wang Q, Kuninobu M, Ogawa HI, Kato Y. Degradation of volatile fatty acids in highly efficient anaerobic digestion. Biomass Bioenerg 1999; 16(6):407-416. 